\title{
LIETUVOS AUKŠTŲJŲ MOKYKLŲ STUDENTŲ KŪNO MASĖS INDEKSO VERTINIMAS
}

\author{
Valerij Dobrovolskij, Rimantas Stukas \\ Vilniaus universiteto Medicinos fakulteto Visuomenès sveikatos institutas
}

Raktažodžiai: studentai, kūno masès indeksas.

\begin{abstract}
Santrauka
Vienas iš mitybos būklę ir sveikatą apibūdinančių rodiklių yra kūno masès indeksas. Antsvoris ir nutukimas - viena iš rimčiausių visuomenès sveikatos problemų, turinčių reikšmingą poveikị sergamumui ir mirtingumui visame pasaulyje. Darbo tikslas - nustatyti ir įvertinti Lietuvos aukštujų mokyklų studentų kūno masès indeksą. Tyrimas atliktas 2013 metais. Tikslinè grupé - Lietuvos aukštujų mokyklų dieninių studijų studentai. Buvo išdalyta ir surinkta 1910 anketų, iš jų 86 užpildytos netinkamai, likusios 1824 buvo panaudotos tyrime. Statistinio reikšmingumo lygmuo buvo pasirinktas $\alpha=0,05$, rezultatai buvo vertinami kaip statistiškai reikšmingi, kai $\mathrm{p} \leq 0,05$. Tyrimo rezultatai parode, kad normalu kūno svorị turi didžioji dalis studentų (78,5 proc.), antsvorị - beveik kas dešimtas studentas (9,3 proc.), nepakankamą svorị - 11,4 proc. studentų. Antsvorị turi daugiau vaikinai bei vyresni studentai, nepakankamą kūno svorį - daugiau merginų bei humanitarinių, socialinių ir biomedicinos mokslų srities studentų.
\end{abstract}

\section{Ivadas}

Antsvoris ir nutukimas - viena iš rimčiausių visuomenès sveikatos problemų, turinčių reikšmingą poveikị sergamumui ir mirtingumui visame pasaulyje. 2014 metais 39 proc. suaugusių ( 38 proc. vyrų ir 40 proc. moterų) pasaulio gyventojų turejjo antsvorị. Nutukimas ir antsvoris didina cukrinio diabeto, širdies ir kraujagyslių, vėžinių reprodukcinès sistemos ligų ir osteoartrito išsivystymo riziką [1].

Sveika gyvensena - fizini pajègumą, sveikatą palaikančių, tausojančių ir stiprinančių kasdienių ịpročių visuma: kasdienis fizinis aktyvumas, miego, mitybos, darbo ir poilsio režimo laikymasis, svaigiujų gèrimų, narkotikų, rūkalų nevartojimas ir kt. [2].
Dèl netinkamų gyvensenos ịpročių ateityje gali padaugèti lètinių susirgimų, tokių kaip kraujagyslių sistemos ligos, padidèjęs kraujospūdis, antrojo tipo diabetas, insultas, kai kurių tipų vėžys, skeleto raumenų sistemos ir net ịvairūs psichikos sveikatos sutrikimai. Ilgainiui tai gali neigiamai paveikti gyvenimo trukmę ES ir dèl to gali žymiai pablogèti daugelio žmonių gyvenimo kokybė [3].

Vienas iš mitybos būklę ir sveikatą apibūdinančių rodiklių yra kūno masès indeksas (toliau - KMI). Kūno svoris vertinamas pagal KMI. Jei KMI mažiau nei 18,5 - kūno svoris nepakankamas, jei KMI nuo 18,5 iki 24,9 - kūno svoris normalus, jei KMI nuo 25 iki 29,9- turima antsvorio, ir jei KMI daugiau arba lygu 30 - žmogus yra nutukęs [4].

Tiriant studentų kūno masès indeksą skirtingose šalyse, nustatyta, kad 70-80 proc. studentų turi normalų kūno masès indeksą. Priklausomai nuo šalies, vidutiniškai penktadalis studentų turi antsvorį. Lenkijoje normalų KMI turèjo 74 proc. merginų ir 68 proc. vaikinų [5]. Kroatijoje daugumos studentų (80,7 proc.) KMI normalus, tik 3,8 proc. studenčiu ir 21,9 proc. vaikinų turèjo antsvori [6]. Švedijoje antsvorị turèjo 10 proc. studenčių ir 22 proc. studentų [7]. Serbijoje 76,4 proc. studentų KMI buvo normalus ir 11,5 proc. turejjo antsvori [8]. Tačiau yra šalių, kur antsvorị turinčių studentų daugiau, nei rodo mūsų tyrimo rezultatai. 2010 metais Graikijoje atlikto tyrimo duomenimis, 32,1 proc. vaikinų ir 8,4 proc. merginų, studijuojančių mediciną, turejjo antsvorị, o nutukusių buvo atitinkamai 5,9 ir 1,5 proc. studentu [9]. Švedijoje 30 proc. vaikinų ir 13 proc. merginų turejo antsvorị ar buvo nutukę [10]. Rusijoje matomas didelis studentų nepakankamo kūno svorio paplitimas - 36,2 proc. turi per mažą KMI [11].

Darbo tikslas - nustatyti ir ịvertinti Lietuvos aukštųju mokyklų studentų kūno masès indeksą.

\section{Tyrimo medžiaga ir metodai}

Tikslinè populiacija - Lietuvos aukštujų universitetinių mokyklų studentai. Atsižvelgiant ị tai, kad didžioji dalis studentu studijuoja valstybiniuose universitetuose ir stu- 
dijuoja Vilniuje, buvo nuspręsta, kad tyrimo populiacija Vilniaus valstybinių universitetinių aukštųjų mokyklų studentai, tyrimo metu studijuojantys aukštosiose mokyklose pagrindinèse (bakalauro) ir magistrantūros studijose. Sudaryta atsitiktinè imtis. Buvo išdalyta ir surinkta 1910 anketų, iš jų 86 užpildytos netinkamai, likusios 1824 buvo panaudotos tyrime. Anketinè apklausa buvo atlikta 2013 metais. Anketos buvo pildomos vietoje, aukštosiose mokyklose, studentams sutikus dalyvauti tyrime. Respondentų buvo prašoma nurodyti savo ūgị ir svorị, kuriais remiantis buvo apskaičiuojamas kūno masès indeksas, kūno masę kilogramais padalinus iš ūgio metrais kvadratu. Jei KMI mažiau nei 18,5 - kūno svoris nepakankamas, jei KMI nuo 18,5 iki 24,9 - kūno svoris normalus, jei KMI nuo 25 iki 29,9 - antsvoris ir jei KMI daugiau arba lygus 30 - nutukimas [19].

Statistinei analizei atlikti naudoti tradiciniai aprašomosios statistikos metodai. Tolydžių duomenų charakteristikoms apibūdinti buvo skaičiuoti vidurkiai, mediana, standartinis nuokrypis (SN). Kategorinių duomenų dažnis vertintas absoliučiais skaičiais ir procentais, įverčio intervaliniam vertinimui apskaičiuotas 95 proc. pasikliautinasis intervalas. Kategorinių duomenų analizei panaudotas $\chi^{2}$ ir Fisherio tikslusis metodas. Statistinio reikšmingumo lygmuo buvo pasirinktas $\alpha=0,05$, rezultatai buvo vertinami kaip statistiškai reikšmingi, kai $\mathrm{p} \leq 0,05$. Duomenų tvarkymui ir statistinei analizei atlikti naudoti

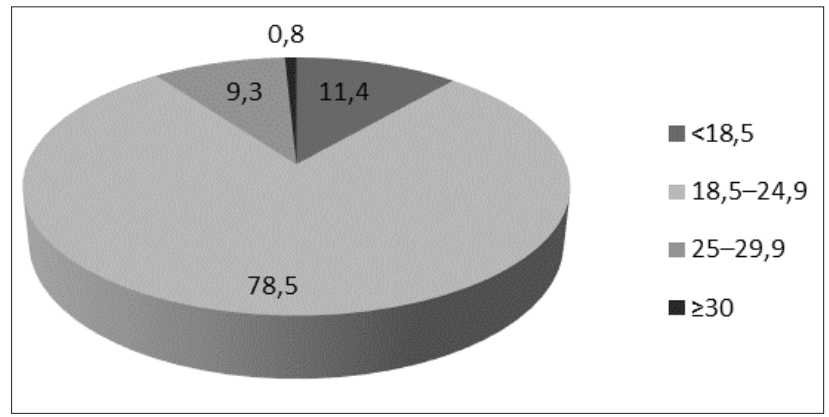

1 pav. Studentų pasiskirstymas (proc.) pagal kūno masès indeksą

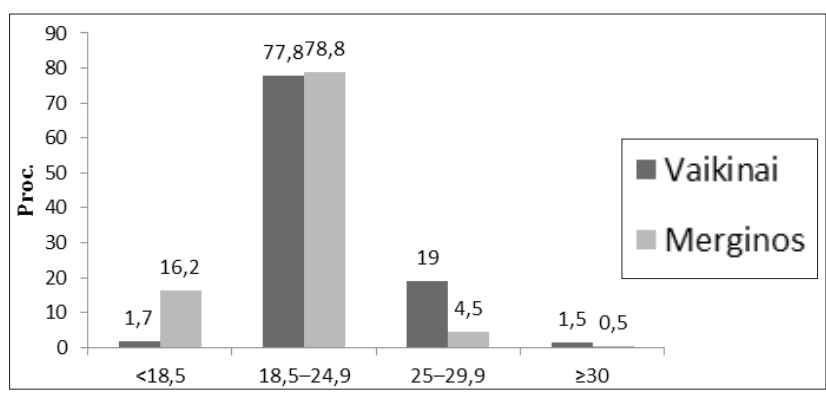

2 pav. Studentų pasiskirstymas (proc.) pagal KMI priklausomai nuo lyties $\left(\chi^{2}=166,941 ; \mathrm{df}=3 ; \mathrm{p}<0,001\right)$ statistiniai paketai SPSS (v. 22.0) ir WinPepi (v. 11.26).

\section{Rezultatai}

Apskaičiavus studentų KMI nustatyta, kad normalų kūno svorị (KMI 18,5-24,9) turi didžioji dalis studentų (78,5 proc.), antsvorị (KMI 25,0-29,9) - beveik kas dešimtas studentas $(9,3$ proc.), nepakankamą svorị $(\mathrm{KMI}<18,5)$ - 11,4 proc. studentų (1 pav.).

Nustatyta, kad didžiosios dalies merginų ( 78,8 proc.) ir vaikinu $(77,8)$ kūno svoris normalus. Tačiau antsvorị turi gerokai daugiau vaikinų (19 proc.) nei merginų (4,5 proc.), skirtumas statistiškai reikšmingas $\left(\chi^{2}=98,077 ; \mathrm{df}=1 ; \mathrm{p}<\right.$ $0,001)$, o nepakankamą kūno svorị turi daug daugiau merginų ( 16,2 proc.) nei vaikinų ( 1,7 proc.), skirtumas statistiškai reikšmingas $\left(\chi^{2}=82,381 ; \mathrm{df}=1 ; \mathrm{p}<0,001\right)(2$ pav. $)$.

Analizuojant studentų KMI pagal amžių nustatyta, kad antsvorio daugiau turi vyresni (10,3 proc.) nei jaunesni $(6,2)$ studentai, skirtumas statistiškai reikšmingas $\left(\chi^{2}=\right.$ $6,715 ; \mathrm{df}=1 ; \mathrm{p}=0,01)(3 \mathrm{pav}$.$) .$

Vertinantstudentų KMI pagal gyvenamająaplinką, nustatyta, kad nepakankamą kūno svorị turi daugiau studentų, gyvenančių nuomojamame gyvenamajame būste (14,4 proc.), nei gyvenančių bendrabutyje ( 8,3 proc.), skirtumas stitistiškai reikšmingas $\left(\chi^{2}=9,203 ; \mathrm{df}=1 ; \mathrm{p}=0,002\right)$ ( 1 lentelè).

Analizuojant studentų KMI pagal užimtumą ir studijų finansavimo pobūdị statistiškai reikšmingų skirtumų tarp

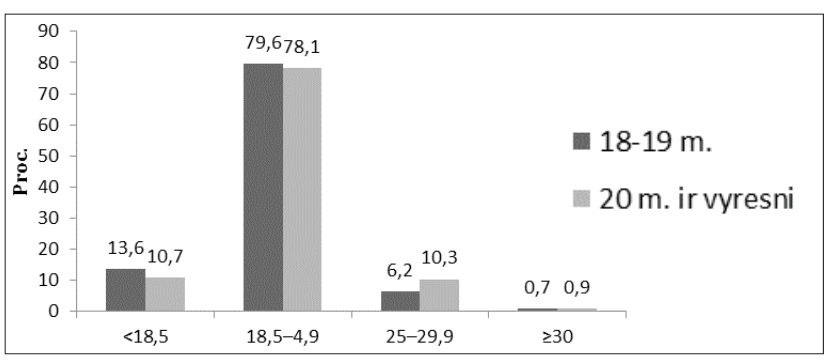

3 pav. Studentų pasiskirstymas (proc.) pagal KMI priklausomai nuo amžiaus $\left(\chi^{2}=8,810 ; \mathrm{df}=3 ; \mathrm{p}=0,032\right)$

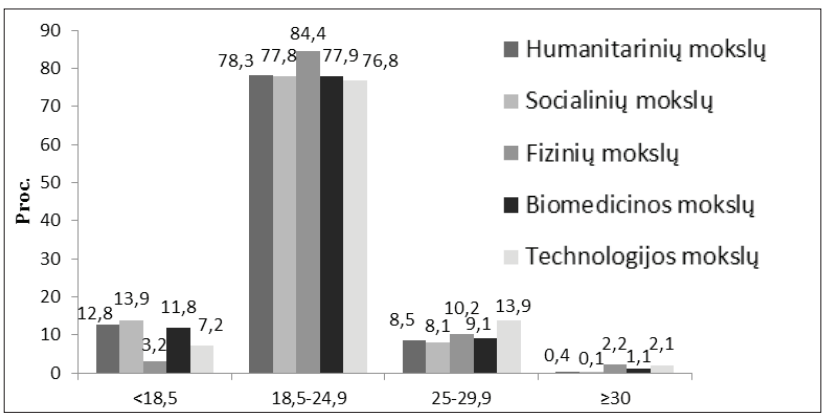

4 pav. Studentų pasiskirstymas (proc.) pagal KMI priklausomai nuo mokslo srities $\left(\chi^{2}=37,617 ; \mathrm{df}=12 ; \mathrm{p}<0,000\right)$ 
1 lentelè. Studentų pasiskirstymas (proc.) pagal KMI priklausomai nuo užimtumo, gyvenamosios aplinkos ir studijų finansavimo pobūdžio

\begin{tabular}{|c|c|c|c|c|c|c|c|c|}
\hline \multirow[t]{3}{*}{ Studentų grupės pagal požymius } & \multicolumn{8}{|c|}{ Kūno masès indeksas } \\
\hline & \multicolumn{2}{|c|}{$<18,5$} & \multicolumn{2}{|c|}{$18,5-24,9$} & \multicolumn{2}{|c|}{$25,0-29,9$} & \multicolumn{2}{|r|}{$\geq 30$} \\
\hline & $\mathbf{n}$ & Proc. & $\mathbf{n}$ & Proc. & $\mathbf{n}$ & Proc. & $\mathbf{n}$ & Proc. \\
\hline UŽIMTUMAS & \multicolumn{8}{|c|}{$\left(\chi^{2}=4,381 ; d f=3 ; p=0,223\right)$} \\
\hline Dirba & 60 & 13,8 & 336 & 77,2 & 37 & 8,5 & 2 & 0,5 \\
\hline Nedirba & 143 & 10,6 & 1063 & 78,9 & 128 & 9,5 & 13 & 1,0 \\
\hline GYVENAMOJI APLINKA & \multicolumn{8}{|c|}{$\left(\chi^{2}=13,998 ; d f=9 ; p=0,122\right)$} \\
\hline Gyvena bendrabutyje & 45 & 8,3 & 440 & 81,5 & 52 & 9,6 & 3 & 0,6 \\
\hline Gyvena su tėvais & 76 & 12,3 & 475 & 76,9 & 60 & 9,7 & 7 & 1,1 \\
\hline Nuomojasi gyvenamaji plotą & 65 & 14,4 & 346 & 76,7 & 38 & 8,4 & 2 & 0,4 \\
\hline Kita & 18 & 10,1 & 143 & 79,9 & 15 & 8,4 & 3 & 1,7 \\
\hline STUDIJU FINANSAVIMO POBŪDIS & \multicolumn{8}{|c|}{$\left(\chi^{2}=2,354 ; d f=3 ; p=0,502\right)$} \\
\hline Valstybės finansuojamos & 153 & 11,0 & 1106 & 79,2 & 125 & 9,0 & 12 & 0,9 \\
\hline Valstybès nefinansuojamos & 48 & 12,7 & 287 & 75,7 & 41 & 10,8 & 3 & 0,8 \\
\hline
\end{tabular}

grupių nenustatyta (1 lentelè).

Analizuojant studentu KMI pagal mokslo sritis nustatyta, kad statistiškai reikšmingai daugiau technologijos srities studentu (13,9 proc.) nei socialinių mokslų srities studentu $\left(8,1\right.$ proc.) turi antsvori $\left(\chi^{2}=5,973 ; \mathrm{df}=1 ; \mathrm{p}=\right.$ $0,015)$. Nepakankamą kūno svorị turi statistiškai reikšmingai daugiau humanitarinių $\left(\chi^{2}=12,341 ; \mathrm{df}=1 ; \mathrm{p}<0,001\right)$, socialiniu $\left(\chi^{2}=16,287 ; \mathrm{df}=1 ; \mathrm{p}<0,001\right)$ ir biomedicinos $\left(\chi^{2}=11,529 ; \mathrm{df}=1 ; \mathrm{p}=0,001\right)$ mokslų srities studentų nei fizinių mokslų srities studentų (4 pav.).

\section{Išvados}

1. Didžioji dalis studentu ( 78,5 proc.) turi normalu kūno svorị, beveik kas dešimtas studentas turi antsvorị.

2. Antsvorị turi daugiau vaikinai bei vyresni studentai, nepakankamą kūno svorị - daugiau merginų bei humanitarinių, socialinių ir biomedicinos mokslų srities studentų.

\section{Literatūra}

1. World Health Organization, Global status report on noncommunicable diseases 2014. Prieiga per internetą: http://apps. who.int/iris/bitstream/10665/148114/1/9789241564854 eng. pdf?ua $=1$

2. Gudžinskienė V. Mokymas sveikai gyventi: teoriniai ir praktiniai aspektai. Mokymo metodinė priemonè. Vilnius: VPU leidykla, 2007; 118.

3. Europos bendrijų komisija, 2007. Baltoji knyga dèl Europos strategijos su mityba, antsvoriu ir nutukimu susijusiomis problemomis spręsti. Prieiga per internetą: http://ec.europa. $\mathrm{eu} / \mathrm{health} / \mathrm{ph}$ determinants/life style/nutrition/documents/ nutrition_wp_lt.pdf

4. Stukas R. Sveika mityba. Vilnius, 1999; 24-28, 15-37.
5. Stefańska E, Ostrowska L, Czapska D, Karczewski J, Gołdowska E. Qualitative evaluation of the students diet with normal body mass and overweight at the Medical University in Bialystok. Przeglad Lekarski 2003; 60 Suppl: 631-635.

6. Satalic Z, Baric IC, Keser I. Diet quality in Croatian university students: energy, macronutrient and micronutrient intakes according to gender; Int J Food Sci Nutr 2007 Aug; 58(5): $398-410$.

7. Tengvall M, Ellegard L. Dietary intake in Swedish medical students. Scandinavian Journal of Food and Nutrition 2007; 51 (2): 79-84.

8. Gazibara T, Kisic Tepavcevic D, Popovic A, Pekmezovic T. Eating Habits and Body-weights of Students of the University of Belgrade, Serbia: A Cross-sectional Study. Journal Of Health, Population \& Nutrition 2013; 31(3): 330-333.

9. Chourdakis M, Tzellos T, Papazisis G, Toulis K, Kouvelas D. Eating habits, health attitudes and obesity indices among medical students in northern Greece. Appetite 2010; 55(3): $722-725$.

10. Margareta I. K. von Bothmer and Bengt Fridlund. Gender differences in health habits and in motivation for a healthy lifestyle among Swedish university students. Nursing and Health Sciences 2005; 7: 107-118.

11. Lakshin AM, Kozevnikova NG. Pitanije kak faktor formirovanija zdorovja i rabotasposobnosti studentov. Voprosy pitanija 2008; 6: 44-45.

\section{BODY MASS INDEX ASSESSMENT OF LITHUANIAN STUDENTS}

\section{Dobrovolskij, R. Stukas}

Key words: students, body mass index.

Summary

The link between obesity, poor health outcomes and all-cause 
mortality is well established. Overweight and obesity are major risk factors for a number of chronic diseases, including diabetes, cardiovascular diseases and cancer. A crude population measure of obesity is the body mass index (BMI), a person's weight (in kilograms) divided by the square of his or her height (in metres). A person with a BMI of 30 or more is generally considered obese. A person with a BMI equal to or more than 25 is considered overweight. The aim of the research was to determine and asses body mass index among student in Lithuanian high schools. Target population - the students of the Lithuanian universities. 1910 questionnaires were distributed and collected; 86 of them were filled in improperly, the 1824 were used in the study. Students surveyed in 2013. The level of statistical significance was chosen $\alpha$
$=0.05$; the results were assessed as statistically significant when $\mathrm{p}$ $\leq 0.05$. Statistical analysis performed by using SPSS and WinPepi programs. The results showed that majority (78.5 percent) of the students had normal BMI, 9.3 percent of students were overweight and 11.4 percent had lack of weight. More males, compared to females, were overweight.

Correspondence to: rimantas.stukas@mf.vu.lt

Gauta 2015-05-25 